\title{
'The unfinished business': Exploring teachers' views on gender and pedagogical practices in public preschools in Nairobi county, Kenya
}

\author{
Juliet Njeri Muasya* and Teresia Wakesho Kazungu \\ School of Education, University of Nairobi, P.O. Box 25304-00100 Nairobi, Kenya. \\ Accepted 12 March, 2018
}

\begin{abstract}
Early years of a child, especially during Early Childhood Education (ECE), is a critical period facilitating the formation of gender identity and stereotypes, which could affect the appropriate development of a child. Yet, to date, most studies on gender and pedagogy in ECE have been done outside Africa, and so far none in Kenya. The aim of this study was to explore the views of preschool teachers in regard to gender and pedagogical practices in their teaching of English language through the use of in-depth interviews. Data analysed from interviews transcripts with 15 (14 females and 1 male) preschool teachers shows that in their use of role play, songs, poems, storytelling, group work to teach English language, there are visible aspects of gender stereotypes, more emphasis on masculinity status as compared to femininity. Although preschool teachers encourage children to work in groups of boys and girls, parents seem to be influencing children's choice of their role play. Further, the findings show that although preschool teachers are to some extent gender sensitive, they tend to have limited knowledge on how to use gender responsive pedagogy when teaching boys and girls English language, which confirms the yet 'Unfinished Business of 21st Century'. There is need to train preschool teachers on how to effectively use gender pedagogical practices for purposes of achieving equality as postulated in the 2016 United Nations Sustainable Development Goals.
\end{abstract}

Keywords: Gender and pedagogy, gender, gender roles, Early Childhood Education, preschool education.

*Corresponding author. E-mail: julietnjerim@gmail.com. Tel: 254-724766431.

\section{INTRODUCTION}

International conventions on education, Dakar Framework for Action 2000 and Millennium Development Goals (MDG) 2000 shows that gender equity goals in education should have been achieved by 2015, however, this is yet to be realised. The question is: To what extent has the MDG Goal 4 on gender equality and empowerment been achieved and what obstacles could have hindered this achievement? This is what Hillary Clinton in 2014 refers to as 'Unfinished Business of the $21^{\text {st }}$ Century', meaning there is still lack of full participation of male and female, girls and boys in education in terms of access, performance, retention and transition, thus, hindering the achievement of gender equality. United Nations Sustainable Development Goals (SDGs) 2016 calls on governments to ensure that girls and boys have access to quality early childhood development and care in education (UNICEF, 2016). Studying boys and girls in their early years is key to achievement of equality because this is the time when children are beginning to form gendered perceptions of their abilities (Slater, 2003). And, since gender stereotype and bias are well developed and defined between 5 to 7 years, this makes preschool years, which is a foundation of holistic learning, a critical period (Martin and Ruble, 2004; Piscalho et al., 2011) to undertake this study.

In 2006, UNICEF challenged governments, committed to education and gender equality to be aware that early years are most critical in a child's development. While emphasising on the importance of gender and ECE, during the 2006 United Nations Girls Education Initiative 
(UNGEI) meeting held in Cairo, UNICEF Deputy Executive Director, said: "Gender equality must be addressed from the first years of a child's life." In their support, Pohjolainen and Westendorff (2014) noted the need to understand and address gender inequality beginning from early childhood. This means, it is vital to address gender issues affecting boys and girls in their homes, pre-schools and other levels of education if gender equality has to be achieved. A quality ECE programmes should instill the notion of gender equality among boys and girls for purposes of achieving sustainable development. Although Kenya has made progress in enhancing access, retention, quality completion rates and gender parity in education, however, the sectors continue to encounter challenges, particularly in regard to gender and pedagogical practices. In an attempt to deal with such challenges, the social pillar in Kenya's Vision 2030 aims at creating a comprehensive, equitable and just society based on democratic rights. Under this pillar, education and training is expected to be a catalyst towards the realisation of Kenya's Vision 2030 (Republic of Kenya, 2013). The question is: To what extent are preschool teachers equipped with relevant knowledge and skills to deal with gender and pedagogical issues during the critical period of the development of a child? Thus, this study was guided by the following objective: To explore preschool teacher's views regarding gender and pedagogical practices in public primary schools in Nairobi county.

\section{Gender and pedagogy}

Gender refers to the socially constructed characteristics norms, roles, relationships, responsibilities, behaviors, activities, and attributes that a society or culture considers appropriate for male and females, boys and girls (UNESCO, 2003). Gender varies one society and culture to another and changes with time. While pedagogy relates to what, how or practice (the art, science or the craft) of educating, teaching, care giving of boys and girls by ECE staff (Siraj-Blatchford, 2004; Wall et al., 2015a, b; Warin and Adriany, 2015). Pedagogy also refers to the instructional techniques and strategies, which facilitate teaching and learning process (Wall et al., 2015a, b), thus enables boys and girls to effectively acquire knowledge, skills, attitudes and dispositions within a particular education context (Siraj-Blatchford et al., 2002; McMonagle, 2012; Wall et al., 2015a, b). In their comparative study on pedagogical practices Wall et al. $(2015 \mathrm{a}, \mathrm{b})$ noted that the quality of interactions between teachers and children stimulate early learning. Anders (2015) states that boys and girls learn and develop during the early years, depending on what is taught and how it is facilitated. Thus, Wall et al. (2015a, b) advises educators to make sure that teaching remain child-centred, developmentally appropriate, with emphasis on play based learning where girls and boys are given equal opportunities to freely chose play activities (Siraj-Blatchford, 2004).

Gender pedagogy, gender sensitive pedagogy and gender flexible pedagogy are approaches mostly used in Swedish preschools. These concepts refer to art of teaching strategies and practices meant to enhance achievement of gender equity and equality (Samuelsson, 2009; Karlson and Simonsson, 2011). Gender flexible pedagogy incorporates ideals of using alternative forms of masculinities and femininities, while considering gender within the curriculum, resources and activities (Warin and Adriany, 2015). Gender pedagogy allows girls and boys to be given similar opportunities, rights, tasks to develop and explore their abilities and interest without limitations imposed by gendered stereotype roles, norms, and ideas imposed by teachers and other forces (Samuelsson, 2009; Karlson and Simonsson, 2011). Since children's perceptions of gender roles are limited to certain stereotypes, the task of preschool teachers is to present children with available options, guiding them to become critical thinkers of their day to day lives (Pohjolainen and Westendorff, 2014), irrespective of their gender. The way male and female teachers act and speak, their facial and body expressions show children how they are supposed to act as girls and boys. Therefore, teachers need to be aware of their attitudes, gender position and values, and consider these during their interactions with the children (Lowe, 1998 in Pohjolainen and Westendorff, 2014).

Gender Responsive Pedagogy (GPR), a model by Forum of African Women Educationalist (FAWE) and initiated in 2005 aims at creating a gender sensitive teaching environment that enhances and facilitates equal participation of boys and girls. The model requires that teachers take a gendered approach in planning lessons, managing classrooms and evaluating performance so as to give equal opportunity to girls and boys, in order to avoid reinforcement of negative gender stereotypes (Kinyanjui, 2016). Teachers can make classrooms more gender responsive by giving girls and boys opportunities to participate and by using pedagogical practices that demonstrate and allow children to hold open discussions and share relevant values and beliefs (International Bureau of Education-UNESCO, 2017). The need to respect boys' and girls' unique learning and developmental needs require a pedagogy with aspects which engage them with sustained, purposeful talk, use of imaginary and real life experiences (Siraj-Blatchford, 2004).

\section{REVIEW OF LITERATURE}

The review of literature in this section is based on empirical and non-empirical sources drawn from United States of America (USA), Sweden, Spain, Serbia, India 
and Kenya. In their study of gender differences among preschool teachers attitude towards child play in Sweden et al. (2005) reported that women teachers tend to value calm play, emphasising on the importance of social development while preschool male teachers accentuate the significance of physical development. As a kindergarten teacher puts it, girls like to play in larger spaces, while boys prefer playing in any corner (Piscalho et al., 2011). In their findings, Sandberg and PramlingSamvelsvon (2005) noted the importance and need of preschool teachers to create inspiring environments for indoor and outdoor play for boys and girls, if gender equality has to be achieved.

According to Wardle (2007), female teachers organise and participate in activities preferred by girls, such as storytelling, drawing, dramatisation, and role playing. Compared to their male counterparts, female teachers find it more difficult to differentiate between rough and tumble play and aggression, consider the 'ideal child' to be a girl, while the characteristics associated with the 'male side' is perceived to be negative (Tavecchio in Peeters, 2007). Studies have shown that irrespective of their gender, teachers are likely to pay more attention and interact more frequently (either positively or negatively) with men students (Eurydice, 2010; Sadker et al., 2009).

Commenting further on the use of role play, Abril et al. (2008) noted that when dealing with gender segregation through role play in Germany, one teacher observed boys and girls playing in gender separate groups. Further, teachers talked about the importance of children playing together irrespective of their gender. In addition, Aina and Cameron (2011) postulated that when using dramatic play, preschool girls are more likely to choose family roles, while boys choose adventure or action oriented roles. Abril et al. (2008) reported that in many early childhood centers boys were more active, competitive and alert in most of the activities, whereas girls tend to take a more submissive and passive role. McMonagle (2012) found that songs and rhythms are best activities of helping boys and girls develop effective reading and writing skills.

Studies reveal that the differences between how boys and girls engage in play activities is due to chemical, hormonal, and functional differences in their brain (Gurian et al., 2011). Play space is where boys and girls represent either the equal or unequal gender distribution of resources (Abril et al., 2008). Abril et al. (2008) and Gurian et al. (2011) agree that boys are more likely to occupy centre space in the play area whereas girls congregate in groups using smaller spaces. This is because boys' play and games tend to be rougher, involving more running, while girls tend to build low and long structures with blocks (Gurian et al., 2011). Thus, the type of games that boys play, such as ball games, requires more space, whereas girls' games require less space (Abril et al., 2008). In their analysis, Abril et al.
(2008) further reported that boys and girls do not play together because this is not promoted or because they are not familiar with the games where they can cooperate with each other. Further, Gurian et al. (2011) reveal that while boys seem to enjoy action stories, girls like stories that address character feelings as both boys and girls tend to pick same gender peers for friends. Abril et al. (2008) noted that use of stories help in transmitting gender roles and values. According to Aina and Cameron (2011) story telling influences how children learn about gender since it familiarizes them with valued traits and personal characteristics.

A number of researchers namely, Goble et al. (2012) and Daitsman (2011) did their studies in preschools in USA. Using 264 preschoolers (37 to 60 months old), Goble's et al. explored children's choice of gender-typed activities and found that children's choice of toys and activities tend to follow a pattern of gender appropriate preferences. Daitsman used 112 children (3 to 5 years) from a multi-ethnic background. Daitsman's project aimed at helping children move from stereotypes by examining gender mixing through storytelling and drama. Daitsman's findings highlight the central role narratives play in providing a rich avenue of exploring differences and similarities, especially those related to gender preferences and expressions. Findings further show that children's stories influence cultural stereotypes, thus, harboring their potential to move beyond rigid gender boundaries. Daitsman noted that sometimes preschoolers use gender stereotype by segregating themselves by use of different play activities. Goble et al. and Daitsman's studies were done in the USA, thus need to undertake this current study in Kenya.

In India, DeJaeghere and Pellowski Wiger in Miske (2013) reported that although teachers revealed that girls should have the same right as boys in attending schools, there was a tendency of male teachers making reference to boy child asking them more challenging questions, and praising them more frequently as compared to the girl child. Teachers tend to assign children role and task based on gender stereotypes, for example, sweeping or cleaning is assigned to girls, while monitoring the class, re-arranging desks or interacting with adults is given to the boy child (Aikman and Unterhalter, 2007; AndersonLevitt et al., 1998; Leach and Humphreys, 2007). In Serbia, Breneselovic and Krnjaja (2016) found that only girls mentioned being welcomed by their teachers with a kiss, a hug, and physical contact upon arrival at the kindergarten.

In their study done in Catalona, Spain, Vendrell et al. (2014) used 130 ECE teachers to assess how education in gender equity is carried out among 3 to 6 years old children. Results of the study reveal that $44 \%$ of the preschool teachers had between 3 to 10 years of professional experience while $24.8 \%$ of teachers had more than 21 years of experience. The findings further showed that teachers take into consideration gender 
equity aspects in their use of various activities and materials. Although the findings revealed teachers perceptions of male teachers is based on families showing no preference for a male or female teachers, however, ECE continue to be a feminised profession. The study reveal the need to give children freedom of choice, for example, allowing the boy child to play kitchen or to use pink colours, or the girl to play football, for purposes of achieving gender equality.

Trebješanin and Jovanić (2014) in Breneselovic and Krnjaja (2016) in their study done in Serbia, found that it was easy for girls to be obedient because their cultural pattern require that they be 'good, pretty and tidy', a stereotype accepted and sustained in domestic and cultural traditions. According to Miske (2013) the need to have a deeper understanding of gender and pedagogical practices in ECE can only be achieved by examining gendered dimensions of teaching and learning, since there are few studies that have addressed the issue. In addition, Breneselovic and Krnjaja (2016), recommends re-evaluation of ECE practices with a view to improving the enhancement of gender equitable society, thus the need to undertake this study.

Breneselovic and Krnjaja (2016) examined perspectives of 50 children ( 30 girls and 20 boys) from 30 state kindergartens in Serbia, regarding their favorite activities. The data suggest that boys prefer physical loud activities and use of large space for kinesthetic activities and play. The available cultural patterns and space support the clichés of female role to be pretty, cook and raise children, especially during the dramatic play sessions. Girls perform gendered play in the kitchen or hair salon play centres with well established roles and patterns. Some girls were found to be taking the role of 'little teacher', where they are engaged in chores for the teacher, adopt a patronising attitude to other children, and detach themselves from peers. By contrast, boys were free to participate in a culturally accepted way in the 'kitchen' adopting the associated female role, as they abandon the clichéd role models and develop imaginative play. Data suggests that preschool teachers frequently 'favour girls' over boys because girls behave in a way that corresponds to the prevailing 'feminised' kindergarten culture. Irrespective of their gender preschool teachers tend to form closer relationships with the girls. The findings further reveal that gender stereotype activities among preschoolers could lead to rigid rules and prejudices. Similarly, Plan International (2013) found out that since the teaching of ECE is related to 'nurturing' abilities, this could reinforce gender stereotype roles.

Fousiya and Musthafa (2016) used 200 students and 20 teachers drawn from secondary schools of Malappuram district in Kerala, India to examine gender bias in school curriculum and how it affects girls' career aspirations. Their findings drawn from questionnaires and focused group discussions show that teachers are more likely to encourage boys in debates and group discussions, as girls continue to receive minimal attention in various class activities. In their concluding remarks, Fousiya and Musthafa noted that teachers are more likely to reinforce gender bias and discriminatory practices against girls by using different activities. Fousiya and Musthafa did their study in secondary schools and used survey methods, while the current study was done in public preschools in Kenya with 15 preschool teachers participating in in-depth interviews.

Research on pedagogical practices are limited, yet such practices and approaches are implemented in different ways, focusing on particular programmes and context (regions or ECE settings) (Wall et al., 2015b). Most studies on gender and pedagogical practices in ECE have been done outside Africa. Studies done tend to generally emphasis on the importance of gender roles in shaping the lives of preschool children. Thus, the current study is partly in line with the recommendations by Unterhalter et al. (2014) who noted the need to conduct a qualitative study to explore classroom strategies and pedagogical practices based on gender, particularly in preschools.

Studies on gender and pedagogical practices and especially in ECE in Kenya are minimal. Limboro (2014) did a study on gender and teacher pedagogical practices in six primary schools in Nairobi and Kilifi counties using observations, focused group discussion, and mapping methods to generate data. The findings reveal that teachers engage more boys than girls in the learning process, while some teachers humiliate girls in class by using derogatory terms. According to Limboro (2014) gender biased pedagogical practices lead to marginalisation of the girl child, hence limiting their chances of acquiring quality education for sustainable development. However, the study was done in primary schools, while the current one was done in public preschools in Nairobi county. Results from their documentary analysis of Gender Responsive Pedagogy, Wanjama and Njuguna (2015) shows that teachers continue to use traditional teaching methodologies that did not give girls and boys equal opportunities and gender insensitive teaching and learning materials, most of which perpetuate gender stereotypes.

\section{METHODOLOGY}

Cross-sectional study design was used in this study because the information gathered represents what was going on at one point in time (Oslen and St. George, 2004), or produces what Cohen et al. (2000) refers to as a 'snapshot' of a population at a particular point in time. The preschool teachers who participated in this study were sampled from 20 public primary schools in Nairobi county. Through purposive sampling technique, only 15 (1 male and 14 female preschool teachers) from Nairobi 
counties participated in the study. Use of preschool teachers was informed by Warin and Adriany (2015) who noted that the teachers are in a unique position to change the traditional gender roles through gender flexible teaching since they have the opportunity to intervene at the early years of a child's education. The study used indepth interviews to explore preschool teachers' views in regard to activities they use when teaching English Language. By using interviews that engage preschool teachers enhance the provision of valuable insights into gendered norms and practices in schools (Levtov, 2014) and particularly in relation to activities teachers use to teach English Language. Data collected was qualitatively analysed using emerging themes and in line with the aim of the study. In addition to using themes and tables, codes, for instance, FT 1 which means Female Teacher 1 while MT 6 stands for Male Teacher 6 were used as a way of protecting the privacy of preschool teachers who participated in the study.

\section{RESULTS AND DISCUSSION}

\section{Demographic information of preschool teachers}

A total of 15 (14 females and 1 male) preschool teachers participated in this study. This confirms that ECE is a feminised profession as postulated by Plan International (2013), (Vendrell et al., 2014; Breneselovic and Krnjaja, 2016; Joseph and Wright, 2016). Studies have cited cultural aspects, stereotypes, lack of social prestige and low salaries as reasons for the shortage of male teachers in preschools (Abril et al., 2008).

\section{Professional qualifications of preschool teachers}

Information from Table 1 shows that a total of 12 female preschool teachers had attained certificate and diploma in ECE as part of their professional qualification. The only male preschool teacher who participated in this study had Bachelor of Education in ECE.

\section{Teaching experience of preschool teachers}

A total of 7 ( 1 male and 6 female) preschool teachers had 5-10 years, 4 had over 21 years while 3 had 15-20 years of teaching experience (Table 2). Similarly, the current and Vendrell et.al. 's (2014) studies show that only 4 preschool teachers and $24.8 \%$ of the participants had over 21 years of teaching experience respectively. Studies have shown that teaching experience is positively associated with student achievement and school attendance (Kini and Podolsky, 2016). Further, Rice (2010), Kini and Podolsky (2016) are in agreement that on average teachers with more than 20 years of experience are more effective than those with less years.
Table 1. Professional qualifications of preschool teachers.

\begin{tabular}{lcc}
\hline \multirow{2}{*}{ Professional qualifications } & \multicolumn{2}{c}{ Number of teachers } \\
\cline { 2 - 3 } & Male & Female \\
\hline Certificate in ECE & 0 & 6 \\
Diploma in ECE & 0 & 6 \\
Bachelor of Education (ECE) & 1 & 1 \\
Masters of Education (ECE) & 0 & 1 \\
Total & 1 & 14 \\
\hline
\end{tabular}

Table 2. Years of teaching experience.

\begin{tabular}{lcc}
\hline \multirow{2}{*}{ Number of years } & \multicolumn{2}{c}{ Number of teachers } \\
\cline { 2 - 3 } & Male & Female \\
\hline $1-5$ & 0 & 0 \\
$5-10$ & 1 & 6 \\
$10-15$ & 0 & 1 \\
$15-20$ & 0 & 3 \\
Over 21 & 0 & 4 \\
Total & 1 & 14 \\
\hline
\end{tabular}

In particular, Kini and Podolsky (2016) noted that a teacher with over 21 years of experience reduce the incidences of high student absenteeism by $14.5 \%$. As teachers gain experience, students are more likely to do better and improve in school attendance (Kini and Podolsky, 2016).

\section{VIEWS OF PRESCHOOL TEACHERS ON GENDER AND PEDAGOGICAL ACTIVITIES IN ENGLISH LANGUAGE}

Pedagogical activities enable children to acquire and apply knowledge, skills and attitudes to situations they encounter in their day to day life (Ministry of Education, Science and Technology, 2015). The purpose of this study was to explore views of preschool teachers in regard to gender and pedagogical in the teaching of English language.

\section{Limited knowledge on use of gendered activities}

Out of the 15 preschool teachers (14 females and 1 male) interviewed, 10 female teachers use poems, tongue twisters and songs to teach children various concepts in English language. These teachers used animals (sheep), motorcar and boat when reciting poems with the children. For instance,

'...baa baa black sheep song...' (FT 4).

'...Mary hallo teacher, I say come here, look at

my motorcar, it is very dirty...clean my car clean 
my car...'(FT 7).

'...row row row your boat, row row row your boat, gently down the stream ...' (FT 8).

In using poems, two teachers, FT 1 recited the following poem, which shows lack of gender sensitivity in teaching while noting:

'...two little birds, sitting on a tree one named Peter the other named Paul fly away Peter, fly away Paul, come back Peter, come back Paul...' (FT 1).

It is interesting that FT 1 is giving examples of poems using only boys names, 'Paul', and 'Peter', yet this was a class with both girls and boys. This contradicts findings by Breneselovic and Krnjaja (2016) who reported teachers 'favouring girls' over boys, since this corresponds to 'feminised' kindergarten culture. However, preschool teachers need to be sensitive and use the names of both boys and girls when reciting poems to children, since as Samuelsson (2009), Karlson and Simonsson (2011), Kinyanjui, (2016) and International Bureau of Education-UNESCO (2017) revealed the aim of gender sensitive and responsive pedagogy is to give children same rights, tasks and opportunities regardless of their gender.

A total of 6 out of 15 preschool teachers talked of using songs in their teaching of English Language. The following are examples of the songs they used:

'... A B C D song...'.(FT 2).

'...Baa baa black sheep... Have you any wool...

'...Yes sir, yes sir three bags full...' (FT 1).

'... am a girl, I am a good girl, you are a boy, you are a good boy...' (FT 5).

While FT2 and FT 1 sang songs that are gender neutral, FT 5 seems to be aware of the need to refer to boys and girls when singing. The idea of teachers being gender sensitive while teaching English language is further supported by what they said in regard to the compliments they give to boys and girls. They said:

'...I give same compliments to both boys and girls, without mentioning their names and not gender, for instance, well done Jack or Mary...' (FT 4).

'... there are times I am gender specific and will comment, good boy! Or good girl...' (FG 8N).

According to Vendrell et al. (2014), it is important that teachers include gender equity aspects in their use of classroom activities. The idea of being gender sensitive in teaching will according to Pohjolainen and Westendorff (2014) help children become critical thinkers, while dealing with gender issues appropriately.
Two preschool teachers FT1 and FT 2 gave some of the following reasons to explain why they used songs and poems to teach English language:

'...help the children retain information for long
and enhance them to develop talents...improve
their vocabulary and speak fluently in
language...' (FT 1).
'...since the child repeats the song or poem
there is quick retrieval of information and further
helps them to remember the words taught
easily...' (FT 2).

It is clear from the responses of FT 1 and FT 2 that use of songs and poems helps preschool children improve their vocabulary, retain more information, speak fluently and make it easy to retrieve information taught in English language. Preschool teachers need to make use of songs, rhymes and poems more often, since as McMonagle (2012) reported they help the boy and girl children to improve their reading and writing skills.

\section{Gender stereotype and the importance of role models}

There were preschool teachers who felt that girls and boys tended to be inclined into playing the roles in the private domain (family members), that of mother and father. These two preschool teachers, FT 2 and FT 3 said:

'...girls like skipping ropes, girls play for example the role of family members and the roles they play at home...' (FT 2).

'...while boys take the roles of father...' (FT 3). ...boys in my class lag behind in language...I realise that boys get it easily when they imitate a specific boy...they see him as a role model so I encourage them to emulate him...' (FT 7).

As girls play the role of family members, it is clear that boys imitate their father and other boys as their role models as reported by FT 2, FT 3 and FT 7, an indication of the commonly practised gender stereotype roles in the society. This confirms findings by Aina and Cameron (2011) who said that girls choose family roles, while boys go for adventure oriented roles. Such gender stereotype continues to be accepted and sustained in domestic and cultural traditions (Trebješanin and Jovanić, 2014 in Breneselovic and Krnjaja, 2016). Commenting further on the importance of using role models, as revealed by FT 7 , Joseph and Wright (2016) reported that society needs to provide the boy child with role model to look up to, a strategy that can be used to attract minority group (men) into 'feminine' roles and professions, thus lead to the achievement of gender equality.

While responding to the question on whether there are 
situations when preschool teachers engage boys and girls differently while teaching English language, MT 6 says:

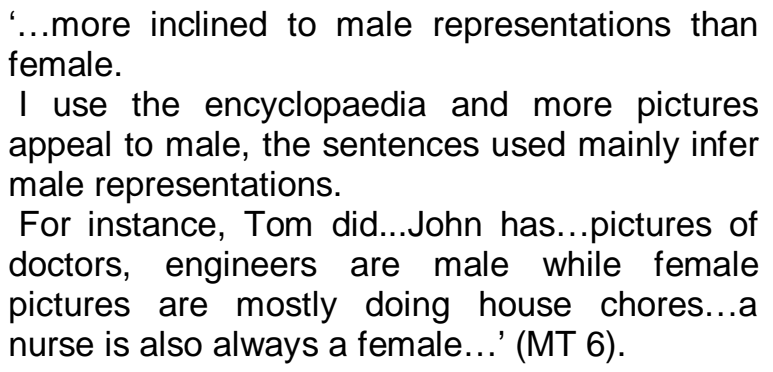

From what MT 6 said it seems that preschool teachers sometimes tend to encourage boys to imitate the role of the father, use pictures that portray boys to be engineers and doctors, while girls play the role of mother and nurse, depicting gender stereotype roles. This confirms research findings by Goble et al. (2012) who found that children's choice of pictures and activities tend to follow gender appropriate preferences. Gender stereotype is well developed and defined at the age when children are in preschools (Martin and Ruble, 2004; Daitsman, 2011). Preschool teachers should encourage boys to show interest in the so called 'feminised professions', for instance, teaching and nursing, since as Joseph and Wright (2016) noted, this is likely to bring positive change in careers usually dominated by females.

\section{Involving boys and girls in role play}

From their responses, it is clear that there are times when preschool teachers engage boys and girls in playing the role of engineer, teacher, shopkeeper, doctors and family members, while arguing that it's fun to do so and important for children's career growth. For instance, FT 9 says: '...l engage all the children in role play where both boys and girls participate...'. This is also reflected in what three preschool teachers said with no regard for a specific gender:

'...they get to act as a teacher and its fun for me...' (MT 6).

'...sometimes they play role of teacher and shopkeeper in the shop corner in our class...I think they like it because it's fun and enjoyable...' (FT 8).

'...children like acting mostly especially acting doctor...' (FT 10).

About five female preschool teachers said that sometimes they request the boy child to play the role of a mother and girls mechanics in a garage. FT 8 expressed the following sentiments:

'...boys are naturally aggressive and fight for materials constantly leaving out the girls...I always have to intervene. Sometimes I request the boys to go play at the shop or kitchen area as the girls have their turn at the garage area and they laugh and say they are not women, though reluctantly, they eventually go...' (FT 8).

Although teachers are aware of boy's masculinity status, however, FT8, FT 10 and MT 6 show the importance of engaging boys and girls in playing the role of teachers, engineer, doctors irrespective of their gender, a way of facilitating the achievement of gender equality among children and teachers in a preschool setting and the society at large. Similarly, Vendrell et al. (2014) and Breneselovic and Krnjaja (2016) found boys choosing and playing freely in the 'kitchen', using pink colours, while girls played football. However, the current study did not explore the reasons which make boys and girls engage in such roles.

\section{Influence of parents vs. masculinity status}

In using peer teaching, FT 1 noted that it is mainly done by the class prefect usually a boy, since children are more likely to give attention and respect more to a boy than a girl. One female preschool teacher emphasis that masculinity status expressed in such terms as 'rough' and 'pushing' of the boy child is likely to discourage them from playing with the girls. FT 10 says:

'...girls don't like playing with boys because they say that their mother say they should not play with boys

...they are rough and will push them until they fall down...' (FT 10).

Assigning the boy child the role of prefect, or monitoring the class (Aikman and Unterhalter, 2007; Anderson-Levitt et al., 1998; Leach and Humphreys, 2007), while the idea of allowing parents (mother or father) to influence the activities of their boys and girls leads to reinforcement of gender stereotyped roles in the society. The idea of being 'rough' and 'pushing' as was noted by FT 10 or masculinity status of the boy child reflects what Abril et al. (2008) refers to as boys being active, competitive and alert in various activities, while girls remain submissive and passive. This could have a negative impact towards the achievement of gender equality.

\section{Separating boys and girls in group activities}

Out of the 15 preschool teachers, 7(6 female and 1 male teachers) said that the groups they used were formed using random, age and ability levels of children, that 
means recognising the quick and slow learners. However, FT 2 noted that for groups to be more effective there was need for preschool teachers to closely supervise children and especially those with low ability (slow learners). Commenting on the idea of mixing girls and boys in groups, MT 6 says:

\begin{abstract}
'...from my interaction with these children, I have observed that the children think that boys are more superior to girls. A practical example is when I asked a girl to play with her male classmate and she declined saying the boys are strong and will hurt her. I asked the boy to let the girl join their football match and they seemed unsure. One even warned her that she could get hurt...' (MT 6).
\end{abstract}

The importance of using groups as a strategy for teaching, especially English language has been postulated by Abriel et al. (2008), Gurian et.al. (2011) and Fousiya and Musthafa (2016). The idea of girls refraining from playing with boys due to their masculinity characteristics (superior, strong) and which hurts the girl child, concurs with the findings by Abriel et al. (2008) and Gurian et al. (2011) who noted boys and girls playing in separate groups. Different scholars have given different reasons, as to why girls and boys play separately. While Gurian et al. (2011) reported that this was due to their biological composition that means that chemical, hormonal, and functional differences in their brain of boys and girls, Abriel et al. (2008) noted that it is because teachers do not promote the idea of playing together or most probably children may be unfamiliar with the games where they can play with each other irrespective of their gender. Any well informed preschool teachers encourage cross-gender activities, this is likely to positively reinforce boys and girls to play with the opposite gender using nonstereotyped toys and other materials, thus support gender responsive learning (Aina and Cameron, 2011).

\section{Storytelling: Avenue of transmitting gendered information}

In the current study story and news telling was used to teach English language. In using storytelling or narratives, the study found out that preschool teachers allow children to read story books, actual telling or reciting of stories, role playing the stories, as they read and recite the poems. Examples of the stories boys and girls like reading and reciting include:

...Cinderella...the three little pigs...fairly tales by age...(FT 2).

...Elephant and friends...foolish hyena...(FT 8).

These stories given by FT 2 and FT 8 are mostly dealing with animals and human beings. Studies have shown that use of narratives in teaching help children to negotiate and reconstruct stereotypes (Daitsman, 2011; Breneselovic and Krnjaja, 2016), thus influencing the cultural and gender stereotypes in their daily lives (Daitsman, 2011). In particular, Daitsman (2011), Aina and Cameroon's (2011) findings highlight the central role narratives play in providing an avenue of exploring gender differences and similarities and further helps in the transmission of valuable gender valued traits and personal characteristics. The type of stories preschool teachers use can make boys and girls develop gendertyped traits and values, for instance, boys' stories are more likely to deal with autonomy and achievement, girls' stories with relationships or support, while male's are of mastery and success, and females stories are usually a direct expression of emotion (Fiese and Skillman, 2000). However, there is need for further studies to explore the type of stories children like or dislike and reasons why they do so, in order to confirm what Gurian et al. (2011) found that boys like action stories, while girls like the ones dealing with specific characters.

\section{CONCLUSION AND RECOMMENDATIONS}

The study findings indicate that preschool teachers attempt to use aspects of gender responsive pedagogy, like for instance involving boys and girls in cross-gender group activities and use of stories to transmit gendered valued information. Some of the preschools teachers are gender sensitive in their teaching of English language and continue to involve boys and girls in activities irrespective of the gender. For instance, preschool teachers asking the boy child to play the role of the mother, and girl child the role of mechanics in a garage. However, gender stereotype practices, for instance, boys getting inclined to play the role of doctors, engineers (public domain), while girls getting more involved in household chores (private domain), use of name of either boys or girls, yet the class has both genders continue to be visible. From the current findings it is evident that parents and preschool teachers continue to influence the role played by boys and girls at home and in school, in terms of the masculinity and femininity status as is reflected in the use of such terms as 'rough', 'pushing', 'aggressive' and 'superiority' of the boy child, which could refrain the girl child from playing with the boys. Overall, it seems that preschool teachers are yet to fully realise, acknowledge and even know how to fully use gender responsive pedagogy in their teaching of English language, which confirms what Hillary Clinton in 2014 noted that the achievement of gender equality in education still remains the 'Unfinished Business of the 21st Century'.

From the findings, the study recommends a need to review and evaluate ECE teachers training curriculum for 
gender responsiveness, since a gender blind curriculum is likely to slow down the achievement of sustainable development. A gender responsive curriculum will make preschool teachers aware of the need to be more sensitive to the needs of girls and boys in their teaching thus, make the children to participate in various activities together irrespective of their gender. Use of gender responsive pedagogy make children grow up knowing that all are equal since discrimination, bias and inequalities is likely to lead to low self esteem, which could affect their participation, performance and achievement. More studies should be done using other activity areas in the curriculum, for instance, Mathematical, Environmental, Christian Religious Education, Islamic Religious Education, Hindu Religious Education, Psychomotor and Creative activities to establish the extent to which preschool teachers are using gender responsive pedagogy. Findings of such studies will go along in informing the Ministry of Education, more so currently (2018) when the new curriculum 2:6:6:3 is being rolled out in pre-primary one and two, grades 1, 2 and 3 in Kenya.

\section{ACKNOWLEDGEMENT}

The study was financed by Deans' Committee Research Grant, University of Nairobi.

\section{REFERENCES}

Abril, P., Cremers, M. Duncan, N. Golubevaite, L. Krabel, J. Lilaite, A. Nordfjell, O. B., Raudonyte, J., and Romero, A. (2008). Gender Loops: Toolbox for Gender Conscious and Equitable Early Childhood Centres. Hinkelsteinsteindruck sozialistische $\mathrm{GmbH}$, Berlin, Germany.

Aikman, S., and Unterhalter, E. (eds.) (2007). Practising gender equality in education, Oxford: Oxfam.

Aina, O. E., and Cameron, P. A. (2011). Why does gender matter? Counteracting stereotypes with young children. Dimensions of Early Childhood, 39(3): 11-19.

Anders, Y. (2015). Literature Review on Pedagogy. OECD, Paris.

Anderson-Levitt, K. M., Bloch, M., and Soumare, A. M. (1998). Inside classrooms in Guinea: Girls' experiences. Bloch, M, Beoku-Betts, J.A., \& Tabachnick, B.R. (Eds.), Women and education in SubSaharan Africa (pp. 99-130). Boulder, CO and London UK: Lynne Rienner Publishers, Inc.

Breneselovic, D. P., and Krnjaja, Z. (2016). Discourses on gender in early childhood and care (ECEC) setting: Equally discriminated against. Journal of Pedagogy, 7(2): 51-77.

Cohen, L., Manion, L., and Morrison, K. (2000). Research methods in education, London and New York, Routledge/Falmer.

Daitsman, J. (2011). Exploring gender identity in early childhood through story dictation and dramatization. Teacher Research in Early Childhood Education, 6(1): 1-12.

Eurydice, T. (2010). Gender Differences in Educational Outcomes: Study on the Measures Taken and the Current Situation in Europe. Brussels: European Commission Education, Audiovisual and Culture Executive Agency.

Fiese, B., and Skillman, G. (2000). Gender differences in family stories: Moderating influence of parent gender role and child gender. Sex Roles: A Journal of Research, 43: 267-83.

Fousiya, P., and Musthafa, M.A. (2016). Gender bias in school curriculum curbs girls career aspirations, IOSR. Journal of Humanities and Social Science (IOSR-JHSS), 21(3): 19-22.

Goble, P., Martin, C. Hanish, L., and Fabes, R. (2012). Children's gender-typed activity choices across preschool social contexts. Sex Roles, 67: 435-451.

Gurian, M., Stevens, K. Henley, P., and Trueman, T. (2011). Boys and girls learn differently: A guide for teachers and parents. San Francisco, USA, Jessey-Bass and John Wiley.

International Bureau of Education-UNESCO (2017). Training Tools for Curriculum Development: A Resource Pack for Gender Responsive STEM Education, UNESCO.

Joseph, S., and Wright, Z. (2016). Men as early childhood educators: Experiences and perspectives of two male prospective teachers. Journal of Education and Human Development, 5(1): 213-219.

Karlson, I., and Simonsson, M. (2011). A question of gender-sensitive pedagogy: discourses in pedagogical guidelines. Contemporary Issues in Early Childhood, 12(3): 274-283.

Kini, T., and Podolsky, A. (2016). Does teaching experience increase teacher effectiveness? A review of the research. University of London, UK. Learning Policy Institute.

Kinyanjui, J. (2016). Mentoring for Kenya's Marginalised Girls, Benefits, Challenges and Policies. Centre for Universal Education at Brookings, The 2016 Echidna Global Scholars, Policy Briefs.

Leach, F., and Humphreys, S. (2007). Gender violence in schools: Taking the 'girls-as-victims' discourse forward. Gender and Development, 15(1): 51-65.

Levtov, R. (2014). Gender Inequalities in Curriculum and Education: Review of Literature and Promising Practices to Inform Education Reform Initiatives in Thailand, Gender Equality and Development, Women's Voice and Agency Research Series 2014, No. 9, World Bank Report.

Limboro, C. (2014). Gender and Teacher Pedagogical practices in schools in Nairobi Informal Settlements and Kilifi County, Kenya, Department of Educational Management, Policy and Curriculum Studies, Kenyatta University.

Martin, C., and Ruble, D. (2004). Children's search for gender cues: Cognitive perspectives on gender development. Current directions in Psychological Science, 13(2): 67-70.

McMonagle, A. (2012). Professional Pedagogy Project, Supporting Every Child's Rights to Early Education, National Early Years Access Initiative (NEYA), USA, DCCC Publishing.

Ministry of Education, Science and Technology (2015). National Curriculum Policy, Republic of Kenya, Nairobi.

Miske, S. (2013). Exploring the Gendered Dimensions of Teaching and Learning, Background Paper for the Education for All and Global Monitoring Report, United Nations Girls Initiative (UNGEI), Working Paper, No. 06, New York, USA.

Oslen, C., and St. George, D. M. (2004). Cross-sectional Study Design and Data Analysis. The Young Epidemiology Scholars Program (YESP), Robert Wood Johnson Foundation and administered by the College Board, lowa and Chicago, USA.

Peeters, J. (2007). Including men in early childhood education: Insights from the European experience. NZ Research in Early Childhood Education, 10: 15-24.

Piscalho, I., Cardona, M. J. Uva, M., and Tavares, T. C. (2011). To Address Gender Equality since the Preschool Education: Research and Practices. International Conference on "Mapping the Gender Equality: Research and Practices, The National and International Perspectives", University of Cyprus, Nicosia.

Plan International (2013). Girls' Learning: Investigating Classroom Practices that promote Girls' Learning. London: Plan UK.

Pohjolainen, L., and Westendorff, A. (2014). Towards a More GenderSensitive Early Childhood Education, Developing Critical Practice through Participatory Workshops, Unpublished Thesis, Bachelor of Social Services, Helsinki Metropolia University of Applied Sciences.

Republic of Kenya (2013). Kenya Vision 2030, Medium Term Plan II, Education and Training 2013-2018. Towards a Globally Competitive and Prosperous Kenya, Nairobi, Kenya.

Rice, J. K. (2010). The Impact of Teacher Experience, Examining the

Evidence and Policy Implications. Brief 11, National Center for Analysis of Longitudinal Data in Education Research, Urban Institute, University of Maryland, USA. 
Sadker, D. M., Sadker, M., and Zittleman, K. (2009). Still failing at fairness: how gender bias cheats girls and boys in school and what we can do about it. New York: Scribner.

Samuelsson, Y. (2009). The Preschool Teacher, Gender Pedagogy and Change, Rethinking the Swedish Preschool Teacher and her work from the Perspective of Sexual Difference Theory, Unpublished Master's Thesis, Linkoping University, Sweden.

Sandberg, A., and Pramling-Samvelsson, I. (2005). An interview study of gender differences in preschool teachers attitudes towards child play. Early Childhood Education Journal, 32(5): 297-305.

Siraj-Blatchford, I. (2004). Quality Teaching in the Early Years. Anning, A., Cullen, J., and Fleer, M. (Eds). Early Childhood Education: Society and Culture. London, Sage Publications: 137-148.

Siraj-Blatchford, I., Sylva, K. Muttock, S. Gilden, R., and Bell, D. (2002). Researching Effective Pedagogy in the Early Years, Research Report 356: Institute of Education, University of London, Department of Educational Studies, University of Oxford, London.

Slater, L. M. (2003). Gender Bias in Elementary Schools: An Examination of Teacher Attitudes, Unpublished Thesis, Department of Educational Psychology, Miami University, Oxford, Ohio, USA.

UNESCO (2003). Gender and education for all. Paris, France, UNESCO.

UNICEF (2006). Gender and Early Childhood Education, UNGEI Technical Meeting, Cairo, Egypt, 2nd November, 2006.

UNICEF (2016). 70 years for every child. The state of the world's children 2016. A fair chance for every child, New York, USA.

Unterhalter, E., North, A., Arnot, M., Llyod, C., Moletsane, L., MurphyGraham, E., Parkes, J., and Saito, M. (2014). Interventions to enhance girls education and gender equality, education rigorous literature review. DFID Research for Development.

Vendrell, R., Capdevila, R., Dalmau, M., Geis, A., and Ciller, L. (2014). Descriptive study on gender equity in early childhood education in Catalonia, Spain. International Journal of Humanities and Social Science, 4(7): 279-290.

Wall, S., Litjens, I. and Taguma, M. (2015a). Pedagogy in early childhood education and care (ECEC): an international comparative study of approaches and policies. Research brief, July 2015 England, OECD, Great Britain.
Wall, S., Litjens, I., and Taguma, M. (2015b). Early Childhood Education and Care, Pedagogy Review, England, OECD, Great Britain.

Wanjama, L. N., and Njuguna, F.W. (2015). Documented Gender Responsive Pedagogy (GRP) Good Best Practices-Case Study. Unpublished Case Study, Nairobi: Kenya.

Wardle, F. (2007). The challenge of boys in our early childhood programs. Early Childhood News, 16(1): 16-21.

Warin, J., and Adriany, V. (2015). Gender flexible pedagogy in early childhood education. Journal of Gender Studies, 26(4): 375-386.

Citation: Muasya, J. N., and Kazungu, T. W. (2018). 'The unfinished business': Exploring teachers' views on gender and pedagogical practices in public preschools in Nairobi county, Kenya. African Educational Research Journal, 6(1): 10-19. 